\title{
Where Is LGBTQ+ in Ontario's Health Care Policies and Programs?
}

\author{
Cameron McKenzie ${ }^{1}\left[\right.$ D $\cdot$ Nick J. Mulé $^{2} \cdot$ Maryam Khan $^{3}$
}

Accepted: 6 April 2021 / Published online: 22 April 2021

() The Author(s), under exclusive licence to Springer Science+Business Media, LLC, part of Springer Nature 2021

\begin{abstract}
Introduction The LGBTQ+ community experiences health inequities that are linked to the social determinants of health (SDH), though the full extent of these health inequities is not fully understood.

Methods This study is a comparative thematic content analysis of the Ontario Ministry of Health and Long-Term Care's (MOHLTC) website and the websites of each of the 14 local health integration networks (LHINs) in 2009 and 2017. It provides a snapshot and evaluation of the amount and type of online content concerning LGBTQ+-specific health needs and determines how well the programs and services aligned with the Ministry's stated priorities and population health/SDH philosophy.

Results We found very little content that suggested a population health approach on the Ministry's website. We also found very little LGBTQ+-specific content on the LHINs' websites in both periods, with two notable exceptions in 2017. Our analysis revealed a persistent emphasis on HIV/AIDS risk containment in the LGBTQ + community over the two periods.

Conclusions We argue that to promote healthy equity, the MOHLTC needs to acknowledge inequalities and intervene through political and social mechanisms that extend beyond HIV.
\end{abstract}

Keywords LGBTQ+ health · Ontario · Population health · Social determinants of health · Health policy

\section{Introduction}

Health inequity refers to the systemic, population-based differences in health outcomes that are "structurally imposed and socially produced" (Graham, 2007, p. 36), and therefore "politically, socially, and economically unacceptable" (World Health Organization, 1978, para. 3). A health equity lens challenges the medical model's emphasis on illnessbased health promotion by emphasizing the social determinants of health (SDH) including class, race, gender, culture and ethnicity, and education among others (Blaxter, 2010; McGibbon, 2012; Raphael, 2016). Sexual orientation and gender identity and expression (SOGIE) often appears on the 'list' of SDH (Blaxter, 2010; McGibbon, 2012), but is

Cameron McKenzie

camckenzie@wlu.ca

1 Faculty of Social Work, Wilfrid Laurier University, Brantford, ON, Canada

2 School of Social Work, York University, Toronto, ON, Canada

3 Faculty of Social Work, Wilfrid Laurier University, Kitchener, ON, Canada not widely recognized as a specific SDH in Canadian public policy (Public Health Agency of Canada, 2018). Further, the health inequities faced by these populations is often disregarded (Mulé et al., 2009). This research examines the extent to which and how well the Ontario Ministry of Health appears to understand and address these health inequities in a comparative two-stage period (2009 and 2017). Through a thematic content analysis, this study evaluates the Ontario government's online communications concerning their policies affecting LGBTQ+-specific health needs. Of importance is that the findings reveal little, if any progress, on the part of the provincial government to adequately address the health needs of the LGBTQ+ populations in Ontario, despite the 8-year period of time between our points of examination. Current and future provincial governments need to be $\operatorname{cog}$ nizant of this moribund in their ongoing health strategies.

\section{Background}

The full extent of health inequities experienced by the LGBTQ+ community is likely not fully understood. Dharma and Bauer (2017) found flaws in definitions and measures of sexual identity in Canadian health surveys; these surveys 
may not capture the nuances of sexual behaviours and gender identity and expression. (See also Cahill \& Makadon, 2017; Wolff et al., 2017). Gay, bisexual, and transgender men, including men who have sex with men (MSM) — but who do not necessarily identify as gay, bisexual, or queercontinue to be at high risk for HIV/AIDS and sexually transmitted infections (Public Health Agency of Canada, 2015). However, the illness-based focus of most health promotion programs and services has overshadowed the LGBTQ+community's diverse health inequities.

Our literature review employed to the following search terms: social determinants of health OR health equity OR well-being; AND sexual orientation, sexual minorit*, LGB*, GLB*, sexual identit*, gender identit*, and gender expression. We searched titles, abstracts, and subject headings in 17 academic databases through ProQuest from January 1, 2009 to October 1, 2020. We used peer-reviewed articles that were in English and referred to North America only. We excluded book reviews, commentaries, and articles that examined on lifestyle issues (e.g., smoking, substance use, individual behaviours) or had a disease-specific focus other than HIV/AIDS (e.g., cancer patients). Furthermore, our search required that articles focused explicitly on sexual minorities and/or LGBTQ+ populations. Lastly, we conducted a manual search on the reference lists in some of the selected articles. Our search yielded 708 results. To make the numbers more manageable, we removed the search term 'well-being'; the search then yielded 186 results. After reviewing titles and abstracts, 159 articles were used for this review.

The extant literature exploring the experiences of LGBTQ+ individuals in health care and social service settings documents significant access related barriers. For example, Tjepkema (2008) found that bisexual individuals, when compared to heterosexuals, experienced marginalization and had many unmet health care needs. As well, lesbians have been found to consult doctors less frequently than heterosexual women and report having fewer pap tests (Tjepkema, 2008). Transgender people, in particular, face unique barriers to accessing appropriate health care regarding reproductive health and transition surgeries (Bauer et al., 2009; Hudson, 2019; Institute of Gender \& Health, 2012; Martinez-Velez et al., 2019). Access to appropriate sexual health education and resources for queer youth are also ongoing health equity concerns (Johns et al., 2019; McKenzie, 2015). One international study indicated "that many queer young people feel unsafe in their schools and regularly experience verbal or physical abuse" (Schmitt, 2012, p. 374). The Canadian Coalition Against LGBTQ+ Poverty recently demonstrated that this community is at risk for poverty (Ross \& Khanna, 2017). Other research also documents mechanisms that create a noted wage gap between sexual minorities and heterosexuals (Waite \& Denier, 2015). Other income-related elements discussed in the literature include housing, food insecurity, and stable employment (Downing \& Rosenthal, 2020; FredriksenGoldsen et al., 2017; Hudson \& Romanelli, 2020; Lazarevic et al., 2016; Logie et al., 2016). The LGBTQ+ community is also at higher risk of homelessness (Abramovich, 2012, 2016). One study estimates that more than one in five (over $20 \%$ ) of youth accessing homeless shelters in Toronto identify as LGBTQ+ (City of Toronto, 2013).

The LGBTQ+ community also faces greater risks of mental health issues such as anxiety and depression, including higher risks of suicide and substance use (Hailey et al., 2020; Kulick et al., 2017; Pakula et al., 2016; Veale et al., 2017), despite evidence that concerted community engagement with this population can have a significant positive impact on mental health outcomes (Crouch et al., 2015; Hudson \& Romanelli, 2020; Kosciw et al., 2014; Toomey \& Russell, 2011).

Overall, our review of the literature found that research tends to address how SDH and SOGIE affect behaviours, rather than conceptualizing SOGIE as an SDH. The emphasis on behaviours is reflected in the literature with the ongoing dominance of HIV/AIDS and mental health, especially regarding substance use.

Some recent research, however, has focused more explicitly on SDH embedded in SOGIE. Literature on 'minority stress' recognizes 'stress processes' including direct experience of prejudice, anticipating rejection, having to remain closeted, and internalized homophobia (Hatzenbuehler, 2009; Meyer, 2003). Krieger (2012) offers the "ecosocial theory of disease distribution" (p. 936) that considers disease distribution in the context of social inequalities, including discrimination, which become embodied and manifest as health inequalities. Thus, there is a fledgling discussion in the literature about turning attention to structural issues such as social stress and exclusion (Gahagan \& Colpitts, 2017; Gower et al., 2019; Hudson \& Romanelli, 2020; Khan et al., 2017; Krieger, 2012; Meyer, 2003; Steele et al., 2017; Zeeman et al., 2017) housing and poverty (Blosnich et al., 2017; Emlet, 2016; Ferlatte et al., 2018) and issues of migrations status and nativity (Allen \& Leslie, 2019; Logie et al., 2016; Oster et al., 2013), including the effects of migration status during COVID-19 (Kline, 2020) We argue that these aspects of health must be prioritized if we are to better understand SOGIE as an SDH and to influence health policy and outcomes for the LGBTQ+ community.

Given that sexual orientation and gender identity and expression are both recognized in the Ontario Human Rights Code (Ontario Human Rights Code, 2020), we were curious to see whether the provincial government in Ontario was utilizing a health equity lens in their health policies regarding the LGBTQ+ populations in the province. With the legal and growing social recognition of the LGBTQ+ populations, we set out to examine the extent to which the province utilized 
both the population health framework and SDH model regarding these groups in their health policies. Two periods of time were chosen to examine provincial health policies providing for an 8-year span to determine progress if any on the part of the government in recognizing the health needs of LGBTQ+Ontarians.

\section{Current Policy and Funding Environment in Ontario}

In Canada's federated system of governance, health care is primarily a provincial and territorial responsibility. With a population of nearly 14 million, Ontario is the most populous and one of the richest provinces in Canada (Statistics Canada, 2019). Ontario's capital, Toronto, is home to one of the largest LGBTQ+ communities in Canada (Clarke \& Coughlin, 2012). According to the 2015 Canadian Community Health Survey, $1.7 \%$ of people between 18 and 59 years old identified themselves as gay or lesbian and $1.3 \%$ of people in that age range identified as bisexual (Statistics Canada, 2016). The Canadian Community Health Survey does not include trans populations and likely underestimates all queer communities, as is often the case with groups of stigmatized people (Clark et al., 2018; Dharma \& Bauer, 2017).

Ontario's Ministry of Health and Long-Term Care decentralized health care oversight by setting up 14 local health integration networks (LHINs) across the province in 2005 (Bill 36, Local Health Integration Act, 2006). The putative reason for this reorganization was that "local people are best able to determine their health service needs and priorities" (Central West LHIN, 2014, para. 1). The LHINs oversee hospitals, community health centres, long-term care facilities, mental health and addiction programs, and other community supports. More recently, the LHINs have taken responsibility for co-ordinating home care services (CBC, 2017).

Gaining authority in 2007, each LHIN determines its own process, format, and frequency of community engagement to develop an annual Local Integrated Health Service Plan. Although LHINs make funding decisions based on local needs and priorities, programs and services must still meet provincial strategic directions (Central LHIN, 2017). All LHINs are listed on a centralized hub (www.lhins.on.ca) that provides links to each of the 14 LHIN websites.

\section{Methods}

This study is a thematic content analysis of the MOHLTC's website and the websites of each of the 14 LHINs. The use of a thematic content analysis is appropriate to this task because themes emerged from the content we reviewed, which in turn guided our analysis. This analysis was conducted on the content at two different points in time, from September to November, 2009 and again from July to November, 2017. During this 8 -year span, Ontario was governed by the Liberals headed by Premiers Dalton McGinty in 2009 and Kathleen Wynne, an 'out' lesbian, in 2017. These two points of data analysis provided us with an opportunity to examine any progress by the same government headed by different premiers during this time period.

Although we recognize that website content allows for only a high-level analysis of intentions and actuality, the web resources we examined represent the Ministry's and the LHINs' public face and a key point of contact to access information. As such, we feel they were an appropriate source of information to understand the Ministry's publicly reported and self-defined approach to administering its mandate. This content analysis also examines the LHINs' funding of services and programs for LGBTQ+. Finally, we examined whether the content changed over the two time periods.

For the website content analysis, we used the following search terms: bisexual, gay, gender identity and expression, homophobia, lesbian, LGBT, transgender, transsexual, Queer, sexuality, and sexual orientation to assess the amount of content related to that population. These terms were entered into each LHIN's website search option. Additionally, these terms were combined with the name of each of the LHINs in a broader Google search engine. For example, on a Google site, we searched for 'Central East LHIN and transsexual'. This was done for each term listed above, i.e. gay, homophobia and combined with the names of the 14 LHINs.

We then assessed the quality of health information judged by whether or not it was contextualized or relevant to a population health/SDH approach and to see whether intersections of social locations (i.e., age, class, disability, ethnicity, gender, gender identity/expression, race, sexual orientation) were recognized. Due to the focus of this research, we searched for named social locations of sexual orientation (LGB+) and gender identity and expression $(\mathrm{T}+)$, as well as any intersections these social locations had with the aforementioned ones. 'Queer' can refer to both sexual orientation and gender identity and expression. From there, we assessed whether what was offered dealt directly with LGBTQ+ as a recognized population with specified health issues. Given the continued dominance of HIV/AIDS in discussions of LGBTQ+ health (Mulé \& Smith, 2014), we also paid particular attention to HIV/ AIDS content and which populations were named in relation to HIV/AIDS. 


\section{Ministry of Health and Long-Term Care Website}

For both time periods, we assessed how well the Ministry's stated commitment to a population health/SDH philosophy aligned with the actual programs and services that were emphasized in the content of the website. To do this, we categorized programs based on their main focus and found that they could be organized under four themes: 'benefits' (e.g., covered health services or programs), 'health issues' (e.g., illnesses or diseases), 'social locations' (e.g., age, race, gender, SDH) and 'systemic operations' (e.g., health service provision functionalities such as accessing services). We also assessed how much emphasis a program or service received on the website by identifying whether their mention occurred in more than one of these categories. Of these categories, we considered social locations to best reflect a population health/SDH philosophy. Discussion of benefits, systemic operations and health issues, on the other hand, were seen to reflect a disease-specific approach.

\section{Local Health Integration Network Websites}

For the analysis of the 14 websites for the LHINs, we also examined the amount and nature of information presented, the programs available, LHIN-led consultation activities and any publications created that were targeted to LGBTQ+ populations. The search terms yielded various sources of data: technical reports produced by the LHINs, meeting minutes, PowerPoint presentations, website content and news releases. LHINs' websites were categorized for the amount and type of LGBTQ+ content for both time periods as follows: (1) minimal or absent LGBTQ+ content, (2) limited LGBTQ+ content and (3) LGBTQ+-specific content. The 'minimal or absent' category applied when LIHNs' website content made no mention of LGBTQ+ or simply listed LGBTQ+ among 'priorities' in its materials, but did not expand on goals or targets. Website content was categorized as 'limited' when there was information about LGBTQ+ unique health needs, but with little evidence of community consultation and/or emphasis on LGBTQ+specific services. Website content was categorized as 'LGBTQ+-specific' when initiatives with a LGBTQ+ focus were highlighted, or a clear articulation of LGBTQ+ diverse health needs was provided, or past and planned collaboration with the community (e.g., advisory committees, community surveys) was indicated.

One author reviewed the contents of the Ministry websites, and the LHIN websites were divided between the other two authors. Because of the straightforward nature of the content sought, that is, presence or absence of information and whether it focused on specific diseases/conditions or social location/ $\mathrm{SDH}$, we did not feel the need for inter-rater reliability tests.

\section{Findings}

Ministry of Health \& Long-Term Care Websites, 2009 and 2017.

Our analysis showed that there are disconnections between the MOHLTC's stated commitment to population health and SDH (MOHLTC, 2017a) and how it implemented policy and delivered programs and services, particularly regarding LGBTQ+. This was evidenced in the categorization of its programs and services that placed a heavy emphasis on service accessibility and delivery over social locations and the particular populations therein. Based on the mention and discussion of social locations, the Ministry's broad policy approach showed less emphasis on SDH in 2017 than in 2009. Our analysis also showed a persistent emphasis on HIV/AIDS risk containment in the LGBTQ+ community over the two periods.

In both time periods, the MOHLTC website highlighted two main areas: governance issues and broad policy approaches. In 2009, the MOHLTC indicated its transition from a centralized to a regionalized approach, but with a process to filter the LHINs' decisions back up to the MOHLTC to ensure overall adherence to its priorities (MOHLTC, 2009a). Eight years later, the MOHLTC elaborated on this 'new' mission and 'stewardship' mandate as providing "the overall direction and leadership for the system, focusing on planning" and "guiding resources to bring value to the health system" (MOHLTC, 2017a, para. 2). This reorganization involved little relinquishment of power: the branches of the MOHLTC were reorganized and decision-making processes were transformed and increasingly distanced from actual health care delivery.

\section{Categorization of Services and Programs}

When the 28 general MOHLTC programs were categorized on the 2009 website, it became clear that 'health issues' (diseases and conditions) dominated, with eight program listings, indicating an illness-based focus. Seven program listings were systemic operations that suggest a preoccupation with operationalizing the programs of the largest and costliest ministry in the province. Additionally, four programs in each of these categories were considered 'combined' when the material of two programs was discussed together under more than one of the categories. Examples of combined programs include immunization discussed under benefits, health issues and systemic operations; organ and tissue donation under health issues and systemic operations and Telehealth Ontario under benefits and systemic operations. These cross-representations of programs in more than one category signified their systemic importance. Only singular, targeted programming for each of children and seniors could be considered for the social locations category in 2009 (MOHLTC, 2009b). 
In 2017, the MOHLTC increased its listings of programs and services to 36 , of which 19 were categorized as systematic operations dealing with provincial health programming administration and providing information and means of accessing services. There was a noted increase in the number of listings in social locations category, specifically within combined programs, such as people with disabilities, children, pregnant women and seniors (MOHLTC, 2017c); yet, LGBTQ+ were not identified separately. Similarly, well over $90 \%$ of the MOHLTC's online publications were focused on specific health issues or benefits rather than issues for specific populations. The only categories in the latter were children, youth and women, identified both in 2009 (MOHLTC, 2009b) and 2017 (MOHLTC, 2017d). All content on women focused on cisgender, heterosexual health needs; none dealt with lesbian, bisexual and trans women's health issues.

Despite what we found to be an increase in content related to social location, it remains the most minimal of all the categories and pays little attention to LGBTQ+ communities. In 2009, the only named social locations were women and seniors. Although children, youth, women and seniors were social locations identified on the 2017 website, little attention was paid to their SDH other than their health needs and access issues, and only minimal attention to how their social location has a direct impact on their health. In short, the Ministry continued to focus heavily on benefits, health issues and diseases and systemic operations categories, with far less attention paid to the social locations of Ontarians.

In summary, programming described on the website did not emphasize population health in 2009 and 2017. Rather, most of the public content focused on accessibility to the provincial health insurance system, medical care, emergency care, home care and prescription drugs. This was particularly the case in 2017 (MOHLTC, 2017a).

\section{HIV/AIDS-Focused Content}

In 2009, the MOHLTC used what is considered sensitive wording in the LGBTQ+ community: gay and bisexual men are explicitly and primarily named ahead of the epidemiological term "Men who have Sexwith Men (MSM) (MOHTLC, 2009c, 2009d,2009e). Concerns have been raised both in the community and the literature regarding the obscuring effect the term MSM can have over men who self-identify as gay or bisexual (Mulé, 2005; Young \& Meyer, 2005). The site identified other specific social locations related to HIV/AIDS, such as people from Africa and the Caribbean, people who use injection drugs, Indigenous people and women (2009d; MOHLTC, 2009e). These populations were discussed only in the context of HIV/AIDS.

Gay and bisexual populations also are included in 2017; yet interestingly, the term MSM is no longer used, despite the fact that MSM continue to be at risk for HIV and are a target for HIV programming in the community. Ideally

room can be made for all these terms, given that health effects can be differentially determined based on behaviour as well as identity (Brennan et al., 2017). Furthermore, these populations are discussed solely within the context of an illness-based program, specifically HIV/AIDS, and the discussion lacks any mention of the intersectionality of the various social locations or SDH (MOHLTC, 2017b). The only area where the website hints at understanding intersectionality is where it discusses the interaction of women with one or more social location such as African, Caribbean, or Indigenous women, and/or women who use injection drugs (MOHLTC, 2017b).

\section{Local Health Integration Network Websites}

Our content analysis of the 14 LHIN websites led to three main findings. First, we found a remarkable lack of LGBTQ+ content in general and little change in the amount and type of content between the two periods. Second, those LHINs that made an effort to consult the LGBTQ+ community also produced the only LGBTQ+-specific content that we found. Third, among those websites with only a limited amount of content, a number of interesting issues directly related to the SDH were raised, somewhat incidentally and usually in documents reflecting an interaction between the LHIN and the LGBTQ+ community or providers working in the community. We categorized this content as 'emergent'. For a comparative breakdown of the amount of LGTBQ+ content on LIHN websites in 2009 and 2017, see Table 1 .

\section{Lack of Content}

As shown in Table 1, in 2009, no LHINs included LGBTQ+-specific content on their websites. Only two had what we categorized as limited content: WaterlooWellington and Toronto Central. Among those LHINs with minimal or absent content, five showed some awareness of specific LGBTQ+ health issues, discussing the community in terms of population health. For example, LHINs identified LGBTQ+ as an underserved and underrepresented

Table 1 Level of LGBTQ+ content on LHIN websites, 2009 and 2017

\begin{tabular}{lll}
\hline & $\begin{array}{l}\text { Number } \\
\text { of LHINs } \\
(n=14)\end{array}$ \\
\cline { 2 - 3 } & 2009 & 2017 \\
\hline Level of content & & \\
Minimal/absent & 12 & 8 \\
Limited & 2 & 4 \\
Specific & 0 & 2 \\
Total & 14 & 14 \\
\hline
\end{tabular}


community (Mississauga Halton LHIN, 2009; Central LHIN, 2009), or as a higher-risk population (Central East LHIN, 2009) with specific health and service needs (South East LHIN, 2009) requiring culturally sensitive attention (Mississauga Halton LHIN, 2009). The Central West LHIN made its first mention of LGBTQ+ populations in 2010.

By 2017, there was a moderate increase in the recognition of LGBTQ+ community health needs. Eight of the LHINs had minimal LGBTQ+ content, four had limited content and two had LGBTQ+-specific content, discussed in more detail below.

The Central LHIN provides an example of minimal content in a 2015 call for proposals for funding new services, because it merely 'listed' LGBTQ+ as one of many equity criteria (Central LHIN, 2015). Similarly, in 2014 and 2017, the Central East LHIN identified the LGBTQ+ demographic among their priority populations in their addictions and mental health strategy (Central East LHIN, 2014, 2016) and referred to LGBTQ+identity in reports (Central East LHIN, 2017). The South West LHIN (2011), Champlain LHIN (2016) and the Erie St. Clair LHIN (2013) identified unique LGBTQ+ mental health and addiction vulnerability, but only in the context of the needs of various minority groups requiring targeted education and programming (Champlain LHIN, 2016; Erie St. Clair LHIN, 2013; South West LHIN, 2011). A commissioned strategic plan for the Erie St. Clair LHIN in 2012 on adult mental health singled out the LGBTQ+ population; however, this was not posted on the website. It was posted elsewhere.

Other LHINs stated a commitment to diversity, while simultaneously showing a serious lack of understanding of LGBTQ+ issues. For example, the Erie St. Clair LHIN did not develop LGBTQ+ content for their website, despite citing 'diversity' as a key principle to "guide the development of health care" (Erie St. Clair LHIN, 2014, para. 1). This LHIN defined 'gender,' as a male/female binary, rather than as a fluid construct. Similarly, a report on the South East LHIN's site addressing SDH makes no mention of sexuality and/or sexual orientation; rather, this document actually conflates gender and sexual orientation (South East LHIN, 2014a, b). The South West LHIN noted that the small number of LGBTQ+in the region made data collection and analysis difficult (Gilliland et al., 2016).

\section{Impact of Community Consultation}

Despite the lack of content on the Waterloo-Wellington LHIN website in 2009, their Integrated Health Service Plan noted that they had completed a survey of the LGBTQ+ community in 2009. The 2017 site provided a detailed report of this consultation with comprehensive recommendations for raising awareness, providing services, improving service integration and increasing provider training. The report also called for the LHINs to provide regional leadership by becoming LGBTQ+ safe spaces and encouraged all health service providers to do the same (Waterloo-Wellington LHIN, 2014, para. 8). This LHIN specifically argued that "[s]exual orientation and sexual identity should be considered social determinants of health as they fundamentally impact health status" (Waterloo-Wellington LHIN, 2014, para. 7).

The Toronto Central LHIN had also developed a 2009 community consultation on mental health and addictions (Toronto Central LHIN, 2009; Zanin, 2009). They developed a voluntary 'citizens' panel' through which the LHIN consulted with its diverse residents on matters related to shaping the health care system. The citizens' panel had representation from many groups including Métis and trans-identified persons (Toronto Central LHIN, 2014, para. 6). By 2017, this LHIN had also undertaken an Aboriginal Health Needs Assessment, including survey questions for two-spirited individuals (Scheim et al., 2013). Indigenous (First Nations, Inuit, and Métis) persons who identify as trans might also use the term two-spirit. This is an umbrella term specifically for First Nations/Indigenous persons who are located between female and male gender roles (Anguksuar, 1997; Balsam et al., 2004). The 2017 content of Toronto Central LHIN site reflected these consultations-with as many as 300 people - in that it recognized the internal diversity of the LGBTQ+ community, including the recognition of health risks associated with different age groups (Toronto Central LHIN, 2016).

\section{Limited Amount of Content}

In 2017, there were four LHINs that posted a limited amount of content. While the Central West LHIN (2010) lacked LGBTQ+-specific content, their report, Diversity and Equity Core Action Group Meeting, indicated a need for more statistics on marginalized communities such as 'LGBT' (Central West LHIN, 2010). In their 2011 and 2012 environmental scans, LGBTQ+ were listed as a priority population (Central West LHIN, 2011, 2012). In 2016, this LHIN's diversity and health equity core action group enumerated ongoing plans to engage the LGBTQ+ community in its meeting notes, including collaboration with a non-profit organization to increase the LIHN's knowledge of LGBTQ+ (Central West LHIN, 2011, 2012, 2016, 2017). Interestingly, meeting minutes also highlighted the "uncomfortability of asking the LGBT questions" and recommended better training for health professionals (Central West LHIN, 2016, p.3).

The Mississauga Halton LHIN, as of 2010, had taken some measures to incorporate LGBTQ+ content, including a reference to positive space training (Mississauga, 2014a). Their website identified the need for "advancing health equity" (Mississauga, 2014a, p. 6) through their Integrated 
Health Service Plan 2016-2019, with specific reference to sexual orientation (Mississauga, 2014b).

\section{Emergent Content}

In addition to the coded content, some interesting information emerged through the analysis. The North East LHIN mentioned LGBTQ+ populations only in 2016 during a board of directors' teleconference meeting. Interestingly, the community needs identified in the discussion were SDH: the need for LGBTQ+-inclusive living environments, staff sensitivity training on LGBTQ+issues, inclusive language and greater community engagement. Members of the teleconference also recognized the often-overlooked issue of inclusive living arrangements specifically for bisexual and transgender residents (North East LHIN, 2016).

Other LHINs made singular or few mentions, but in doing so, they highlighted important health issues in the community. The only content about LGBTQ+ populations posted by the North West LHIN (2017) was a presentation from service providers describing the lack of services and supports, which was corroborated in a Health Quality Ontario's (2016) review of services and programs in this LHIN (Health Quality Ontario, 2016). Health Quality Ontario (HQO) is an agency that exists to educate the Ontario government and the many health care providers on providing the best care possible, based on evidence (research). The aim is also to inform the public about the quality of care and monitor its delivery. The North Simcoe Muskoka LHIN makes a single but interesting mention of LGBTQ+in a description of the inclusion of LGBTQ+ individuals on a 2015 patientcaregiver-family advisory panel (North Simcoe Muskoka LHIN, 2016). These references to LGBTQ+ health concerns arose during the latter point of our analysis indicating an emergence of such concerns and the need for the provincial government to address them.

\section{Discussion}

Our study's aim was to evaluate the amount and quality of LGBTQ+ health content on the MOHLTC's and LHINs' websites in 2009 compared with 2017. Our research reveals that the Ministry's public information about LGBTQ+ health has been consistently minimal between 2009 and 2017. Despite the claim of a population health approach and SDH perspective, the MOHLTC public website content is organized according to an illness framework. Most information about programming focuses on access to health care with very little attention to the SDH; only some specified groups such as people with disabilities, children, pregnant women and seniors were accorded pages on the sites. We also found little change between 2009 and 2017 as to how the MOHLTC presented itself.
This lack of a population health approach hinders equitable health care delivery and our ability to fully address the SDH (Blaxter, 2010; McGibbon, 2012; Raphael, 2016). We argue that a population health approach with an SDH perspective would better recognize the specific health needs of at-risk, minoritized populations (Graham, 2007), such as LGBTQ+. Furthermore, an SDH perspective would consider not only ongoing, specified health concerns such as HIV/ AIDS but also broader health concerns of these populations and SDH such as poverty and discrimination.

Regarding the LHINs, we found that there was very little on LGBTQ+ health except for Waterloo-Wellington and Toronto Central, who significantly increased the amount and quality of their LGBTQ+-specific content in the periods examined. Not surprisingly, these two LHINs had conducted strong community consultations, which improved their content. Among some LHINs that did not consult the community and had very little LGBTQ+ content, contact with community health care providers still managed to raise interesting SDH issues, such as housing and inclusion in family patient care. Given the lack of data and small numbers of LGBTQ+ in some of the regions, community consultation seems particularly important if policy-makers are to fully grasp their health situation.

As mentioned, Waterloo-Wellington LHIN stands out as a leader in community collaboration and advocacy for accessible and appropriate LGBTQ+ services. However, even this LHIN appears to be focused on access to services-an issue identified by Tjepkema (2008) a decade ago—without addressing structural barriers like poverty and social exclusion that are emerging in the literature (City of Toronto, 2013; Ross \& Khanna, 2017). This absence may signal a limited understanding or other barriers for addressing broader SDH that need to be remedied.

The recognition of structural imbalances and the health consequences these produce must inform funding availability for LGBTQ+ health beyond HIV/AIDS containment. This includes a deep-rooted recognition of health challenges premised on society's oppression of LGBTQ+ people that addresses 'eco-social' approaches to health (Krieger, 2012) and contribute to our understanding of social determinates such as 'minority stress' and 'internalized homophobia' (Hatzenbuehler, 2009; Meyer, 2003). As well, an SDH approach that recognizes sexual orientation and gender and identity expression as a specific determinant cannot obscure the diversity of the LGBTQ+ community by subsuming it within an analysis of gender.

How population health and SDH perspectives could be operationalized in a policy context for the LGBTQ+ population is yet to be determined, but it is apparent that these health issues are not reflected on the MOHLTC and most of the LHIN websites. Further research could undertake a literature scope of pressing health and well-being issues 
affecting the LGBTQ+ communities to provide more evidence for the recognition of SOGIE as an SDH and potential policy and programming responses.

The public websites examined are a key resource for public access to services and the policies that shape them. That said, one key limitation of this study is that it can be difficult to extrapolate what is actually happening at the level of community services and programs from the high-level analysis of a website. It is noteworthy that in some cases, the search of the LHIN websites yielded little or no content; yet, a broader Google search combining the name of the LHINs and some of the key words yielded additional LGBTQ+ content that one might have expected to see on the LHIN website. At the very least, this suggests some navigation problems in the design of the websites, which could be discouraging for those looking for information. When those looking for information are part of a vulnerable and stigmatized population, this barrier is particularly troublesome.

In the course of conducting this research, we realized that many of the key organizations, such as AIDS Service Organizations and Rainbow Health Ontario, which provide services to this community, are not funded by the LHINs. The process and rationale behind this might be an interesting area for further research on how LGBTQ+ health is addressed. More research on Rainbow Health Ontario's contribution to LGBTQ+ health equity might also be helpful to understand community needs and to integrate this understanding within the LHINs and the Ministry for moving forward. The improvement in the content of those website where the LHINs consulted the community underscores the importance of a fully representative consultation process.

Some LHINs noted the small number of LGBTQ+ in their regions, and one commented the 'uncomfortability' of discussing sexual orientation and gender and identity expression. These factors, combined with a disproportionate risk for serious health issues and small numbers of people concentrated in urban areas, speak in favour of a population health approach with an SDH perspective to avoid overlooking a stigmatized community. Currently, the Ontario provincial conservative government is in the process of phasing out the LHINs and will need to replace it with an infrastructure and administrative process that does not duplicate the inequities that were produced by the former LHINs.

\section{Call to Action}

We feel that there needs to be a robust SOGIE health equity strategy based on a population health approach. This could be achieved through a three-pronged approach of research, consultation and community mobilization. Our review of the literature suggests that more research on SOGIE and the social determinants of health for the LGBTQ+ community would be beneficial, as would ensuring better research tools with accurate and inclusive definitions and categories. Although sexual orientation is sometimes included in the 'list' of SDH, we question whether the current health literature and policy environment adequately address SOGIE as an SDH. Even experts in SDH research continually neglect SOGIE, sometimes subsuming sexual orientation under the concept of gender (Mikkonen \& Raphael, 2010; Raphael et al., 2020). This heteronormative viewpoint contributes to the invisibility of the health disparities faced by the LGBTQ+ community. Conflating gender and SOGIE also occludes the debates and experiences of fluid sexualities.

Our research shows that when the LHINs made the effort to consult the LGBTQ+ community, they improved their understanding of health disparities. However, for meaningful consultation to occur and for representation within a population approach, a concerted effort must be made on the part of the government to reach out to and connect with LGBTQ+ communities (activists, service providers, academics), doing work on LGBTQ+ health issues that are not necessarily restricted to HIV/AIDS/STIs. Such a consultation was undertaken at the federal level (House of Commons Canada, 2019), yet the results fell short of a nuanced understanding of LGBTQ+ health issues (Mulé, 2020), and was not as localized as the focus here. Government must also be cognizant of focused attention on smaller and/or rural communities where LGBTQ+ presence and resources may be more limited. By engaging in a focused outreach attempt, the government would more consistently be aligning LGBTQ+ health issues with the Ontario Human Rights Code and its inclusion of sexual orientation and gender identity and expression in areas such as service provision (OHRC, 2020). That said, given the limitations of a strictly human-rights approach, LGBTQ+ communities will also have to mobilize to prioritize the broad health issues being experienced and to communicate them with government along with recommendations for redressing. A more inclusive process of health policy development between the government and the LGBTQ+ communities will better examine the issues, determine equitable responses and develop meaningful interventions. The community has a rich and fruitful history of mobilization (including in response to HIV/AIDS) to draw from and needs to rekindle the activism of the past to address the broad health and wellbeing issues of SOGIE communities.

\section{Conclusion}

This study adds to the growing body of scholarship on the health inequities experienced by LGBTQ+ community members. In particular, this study's comparative thematic content analysis conducted on the 14 LHIN websites in 2009 and 2017 suggests that there is meagre Ministry 
content which adequately incorporates and reflects a SDH approach. The findings in conjunction with the extant literature suggest that healthcare policies, programs and services need to shift beyond a purely HIV/AIDS focus and apply a more expansive understanding of health and well-being, which is inclusive of diverse identities and experiences of LGBTQ+individuals. One of the key recommendations urges the federal government to create a population specific approach to support the unmet and inequitable health care needs of LGBTQ+ communities that in turn would influence provincial and territorial administration of health care to these populations.

\section{References}

Abramovich, A. (2012). No safe place to go-LGBTQ youth homelessness in canada: reviewing the literature. Canadian Journal of Family and Youth, 4(1), 29-51.

Abramovich, A. (2016). Preventing, reducing and ending LGBTQ2S youth homelessness: the need for targeted strategies. Social Inclusion, 4(4), 86-96.

Allen, S. H., \& Leslie, L. A. (2019). Considering the role of nativity in the health and psychological wellbeing of Black LGBT adults. Journal of Homosexuality, 66(13), 1769-1796.

Anguksuar, L. R. (1997). A postcolonial perspective on Western [mis] conceptions of the cosmos and the restoration of indigenous taxonomies. In S. E. Jacobs, W. Thomas, \& S. Lang (Eds.), TwoSpirit people: Native American Gender Identity, Sexuality, and Spirituality. (pp. 217-222). University of Illinois Press.

Balsam, K. F., Huang, B., Fieland, K. C., Simoni, J. M., \& Walters, K. L. (2004). Culture, trauma, and wellness: a comparison of heterosexual and lesbian, gay, bisexual, and two-spirit native Americans. Cultural Diversity and Ethnic Minority Psychology, 10(3), 287-301. https://doi.org/10.1037/1099-9809.10.3.287

Bauer, G. R., Hammond, R., Travers, R., Kaay, M., Hohenadel, K. M., \& Boyce, M. (2009). I don't think this is theoretical; this is our lives: how erasure impacts health care for transgender people. Journal of the Association of Nurses in AIDS Care, 20(5), 348-361. https://doi.org/10.1016/j.jana.2009.07.004

Bill 36, Local Health System Integration Act. (2006). Retrieved from http://ontla.on.ca/web/bills/bills_detail.do?locale=en\&BillID $=$ $435 \&$ detailPage $=$ bills_detail_related\&isCurrent $=$ false

Blaxter, M. (2010). Health. (2nd ed.). Policy.

Blosnich, J. R., Marsiglio, M. C., Dichter, M.E., Gao, S., Gordon, A. J., Shipherd, J. C., ... \& Fine, M. J. (2017).Impact of social determinants of health on medical conditions among transgenderveterans. American Journal of Preventive Medicine, 52(4),491-498.

Brennan, D. J., Bauer, G. R., Bradley, K., \& Tran, O. V. (2017). Methods used and topics addressed in quantitative health research on gay, bisexual and other men who have sex with men: a systematic review of the literature. Journal of homosexuality, 64(11), $1519-1538$

Cahill, S. R., \& Makadon, H. J. (2017). If they don't count us, we don't count: Trump administration rolls back sexual orientation and gender identity data collection. LGBT Health, 4(3), $171-173$

CBC. (2017). Ontario said to begin shifting home care responsibilities. Retrieved from https://www.cbc.ca/news/canada/ottawa/ontariohome-care-ccac-lhin-1.4082732
Central LHIN. (2009). "Central LHIN CEO Report Items for Information." Retrieved from http://www.centrallhin.on.ca/boardandgo vernance/boardmeetings/ /media/sites/central/uploadedfiles/ Home_Page/Board_of_Directors/Board_Meeting_Submenu/ CEO-Report-ItemsForInfo-Combined-Finalv1-July-28-09.pdf

Central LHIN. (2015). "Memorandum, call for proposals: complex transitional age youth mental health and addictions services in the Jane Finch Community including dual diagnosis and autism." Request for Proposals \# MHA_1_15-16. Retrieved from http:// www.centrallhin.on.ca/ /media/.../central/.../HSIP\%20MHA_ Transitional_Age_Youth.doc

Central LHIN. (2017). "About us.” Retrieved from http://www.centr allhin.on.ca/aboutus.aspx

Central East LHIN. (2009). "Addictions environmental scan, March 2009." Retrieved from www.centraleastlhin.on.ca/.../ce/.../ Addictions_Environmental_Scan_July_8_09.pdf

Central East LHIN. (2014). "Mental health and addictions strategic aim.” Retrieved from http://www.centraleastlhin.on.ca/en/ priorities/mentalhealthandaddictions.aspx

Central East LHIN. (2016). "Living healthier at home: 2016-2019 integrated health service plan.” Retrieved from http://www.centraleastlhin.on.ca/ priorities/ihsp/IHSP\%202016-2019.aspx

Central East LHIN. (2017). "Ontario Shores Centre for Mental Health Sciences: Master Planning Project Board Presentation." Retrieved from http://www.centraleastlhin.on.ca/ /media/sites/ce/ PrimaryNavigation/BoardandGovernance/BoardMeetings/2017/ April262017/41_OntarioShores.pdf?la=en

Central West LHIN. (2010). "Summary of Central West LHIN's Diversity and Equity Core Action Group Meeting." Retrieved from http:// www.centralwestlhin.on.ca/sitecore/content/Sites/cw/Home/Goals\% 20 and $\% 20$ Achievements/Core\%20Action\%20Groups\%20and\% 20Steering\%20Committees/Diversity_and_Equity_CAG/ /media/ sites/cw/uploadedfiles/Home_Page/Be_Informed/2010.\%2008.\% 2019\%200Diversity\%20Core\%20Action\%20Group\%20Meeting\% 20Highlevel\%20Summary.pdf

Central West LHIN. (2011). "A Framework for Health Service Provider Health Equity Plans: Central West Local Health Integration Network Health Equity Environmental Scan.” Retrieved from http://www.centralwestlhin.on.ca/ /media/sites/cw/Documents/ GoalsandAchievements/CAGs/DiversityAndEquity/2011-1101EnvironmentalScan/HealthEquityEnvironmentalScanQuestionnaire_ updatedMarch292011.pdf?la=en

Central West LHIN. (2012). "Health Equity and Diversity Environmental Scan Results: Highlights.” Retrieved from http://www.centralwes tlhin.on.ca/ /media/sites/cw/Documents/GoalsandAchievements/ CAGs/DiversityAndEquity/2011-11-01-20EnvironmentalScan/ HealthEquityEnvironmentalScanOvervieworResultsJan18High lights.pdf

Central West LHIN. (2014). "FAQ I Ontario's LocalHealth Integration Networks (LHINs)" Retrieved from http://www.centralwestlhin on.ca/About\%20Us/Frequently\%20Asked\%20Questions/About\% 20Ontario\%20LHINs.aspx

Central West LHIN. (2016). "LHIN's Diversity and Health Equity Core Action Group: Meeting Notes." Retrieved from http://www.centr alwestlhin.on.ca/ /media/sites/cw/Documents/GoalsandAchieve ments/CAGs/DiversityAndEquity/2016-09-16-Meeting Mater ials/2,-d-,2016-09-16-HEMeetingNotesJuly 15_V3.pdf?la=en

Central West LHIN. (2017). "Progress Report on Organization Health Equity Plan.” Retrieved from http://www.centralwestlhin.on.ca/ /media/sites/cw/Documents/GoalsandAchievements/CAGs/ DiversityAndEquity/2016-11-18-MeetingMaterials/5,-d,CMHAPeel_HealthEquityReport_2016Update.pdf?la=en

Champlain LHIN. (2016). "Development of Champlain Sub Regions Technical Report.” Retrieved from http://www.champlainlhin.on. $\mathrm{ca} /$ /media/sites/champlain/Goals_Achvmnts/IHSP/SubRegions/ 201612TechReportBI.pdf?la=en 
City of Toronto. (2013). Street needs assessment results. Retrieved from https://www.toronto.ca/legdocs/mmis/2013/cd/bgrd/ backgroundfile-61365.pdf

Clark, B. A., Veale, J. F., Townsend, M., Frohard-Dourlent, H., \& Saewyc, E. (2018). Non-binary youth: access to gender-affirming primary health care. International Journal of Transgenderism, 19(2), 158-169. https://doi.org/10.1080/15532739.2017.1394954

Clarke, M., \& Coughlin, R. (2012). Prevalence of smoking among the lesbian, gay, bisexual, transsexual, transgender and queer LGBTTQ subpopulations in Toronto: The Toronto Rainbow Tobacco Survey TRTS. Canadian Journal of Public Health, 103(2), 32-36.

Crouch, S.R., Waters, E., McNair, R., \& Power, J. (2015). “The Health Perspectives of Australian Adolescents from Same-Sex Parent Families: A Mixed Methods Study." Child: Care, Health and Development, 41(3): 356-364.

Dharma, C., \& Bauer, G. B. (2017). Understanding sexual orientation in Canada: who are we capturing and who are we missing using the statistics Canada sexual orientation question? Canadian Journal of Public Health, 108(1), 21-26.

Downing, J. M., \& Rosenthal, E. (2020). Prevalence of social determinants of health among sexual minority women and men in 2017. American Journal of Preventive Medicine, 59(1), 118-122. https://doi.org/10.1016/j.amepre.2020.01.007

Emlet, C. A. (2016). Social, economic, andhealth disparities among LGBT older adults. Generations, 40(2),16-22.

Erie St. Clair LHIN. (2012). "An Adult Mental Health Strategic Plan for Erie St. Clair 2012-2016." Retrieved from http://www. eriestclairlhin.on.ca/Page.aspx ?id=13216

Erie St. Clair LHIN. (2013). "Mental Health Multi-Year Implementation Framework Report." Retrieved from http://www.eriestclairlhin. on.ca/page.aspx?id=2F185CC63A6340ED87C5D468CBD9D910

Erie St. Clair LHIN. (2014). "The Seven BSO Principles.” Retrieved from http://www.eriestclairlhin.on.ca/GoalsandAchievements/ MentalHealthand\%Addictions/BSO/TheSevenBehaviouralS upportsinOntarioPrinciples.aspx

Ferlatte, O., Salway, T., Trussler, T., Oliffe,J. L., \& Gilbert, M. (2018). Combining intersectionality and syndemictheory to advance understandings of health inequities among Canadian gay,bisexual and other men who have sex with men. Critical Public Health, 28(5),509-521.

Fredriksen-Goldsen, K. I., Kim, H.-J., Bryan, A. E. B., Shiu, C., \& Emlet, C. A. (2017). The cascading effects of marginalization and pathways of resilience in attaining good health among LGBT older adults. The Gerontologist, 57(suppl 1), S72-S83.

Gahagan, J., \& Colpitts, E. (2017).Understanding and measuring LGBTQ pathways to health: A scoping review ofstrengthsbased health promotion approaches in LGBTQ health research.Journalof homosexuality, 64(1), 95-121.

Gilliland, J., Clark, A., Sibbald, S., \& Tillmann, J. (2016). "Understanding Health Inequities and Access to Primary Care in the South West LHIN." Retrieved from https://www.researchgate. net/publication/318990522_Understanding_Health_Inequities_ and_Access_to_Primary_Care_in_the_South_West_LHIN

Gower, A. L., Saewyc, E. M., Corliss, H. L., Kne, L., Erickson, D. J., \& Eisenberg, M. E. (2019). The LGBTQ Supportive Environments Inventory: methods for quantifying supportive environments for LGBTQ youths. Journal of Gay \& Lesbian Social Services, $31(3), 314-331$.

Graham, H. (2007). Unequal Lives: Health and Socioeconomic Inequalities. Open University Press.

Hailey, J., Burton, W., \& Arscott, J. (2020). We are family: chosen and created families as a protective factor against racialized trauma and anti-LGBTQ oppression among African American sexual and gender minority youth. Journal of GLBT Family Studies, 16(2), 176-191.
Hatzenbuehler, M.L. (2009). How does sexual minority stigma "get under the skin"? Apsychological mediation framework.Psychological Bulletin,135(5),707-730.Health Quality Ontario. (2016). "NorthWest LHIN regional quality sessionsummary." Retrieved from http://www.hqontario.ca/Portals/0/ documents/qi/north-west-lhinregional-quality-session-summaryen.pdf

Health Quality Ontario. (2016). "North West LHIN regional quality session summary." Retrieved from http://www.hqontario.ca/ Portals/0/documents/qi/north-west-lhinregional-quality-sessionsummary-en.pdf

House of Commons, Canada. (2019). The Health of LGBTQIA2 Communities in Canada. Retrieved from https://www.ourcommons. $\mathrm{ca} /$ Content/Committee/421/HESA/Reports/RP10574595/hesar p28/hesarp28-e.pdf

Hudson, K. D. (2019). (Un)doing transmisogynist stigma in health care settings: experiences of ten transgender women of color. Journal of Progressive Human Services, 30(1), 69-87. https://doi.org/10. 1080/10428232.2017.1412768

Hudson, K. D., \& Romanelli, M. (2020). "We are powerful people": health-promoting strengths of LGBTQ communities of color. Qualitative Health Research, 30(8), 1156-1170. https://doi.org/ 10.1177/1049732319837572

Institute of Gender and Health, CIHR. (2012). "What a difference sex and gender make: a gender, sex and health research casebook". Canadian Institutes of Health Research, ISBN: 978-1-10019250-5. Retrieved from https://ssrn.com/abstract=2199670

Johns, M. M., Poteat, V. P., Horn, S. S., \& Kosciw, J. (2019). Strengthening our schools to promote resilience and health among LGBTQ youth: emerging evidence and research priorities from The State of LGBTQ Youth Health and Wellbeing Symposium. LGBT Health, 6(4), 146-155.

Khan, M., Ilcisin, M., \& Saxton, K. (2017). Multifactorial discrimination as a fundamental cause of mental health inequities. International Journal of Health Equity, 16(1), 43. https://doi.org/10. 1186/s12939-017-0532-z

Kline, N. S. (2020). Rethinking COVID-19 vulnerability: a call for LGBTQ+ im/migrant health equity in the United States during and after a pandemic. Health Equity, 4(1), 239-242.

Kosciw, J., Palmer, N., \& Kull, R. (2014). Reflecting residency: openness about sexual orientation and/or gender identity and its relationship to well-being and educational outcomes for LGBT students. American Journal of Community Psychology, 55, $167-178$

Krieger, N. (2012). Methods for the scientific study of discrimination and health: an ecosocial approach. American Journal of Public Health, 102(5), 936-945. https://doi.org/10.2105/AJPH.2011. 300544

Kulick, A., Wernick, L., Woodford, M., \& Renn, K. (2017). Heterosexism, depression, and campus engagement among LGBTQ college students: intersectional differences and opportunities for healing. Journal of Homosexuality, 64(8), 1125-1141. https://doi.org/10. $1080 / 00918369.2016 .1242333$

Lazarevic, V., Holman, E. G., Oswald, R. F., \& Kramer, K. Z. (2016). Relations between economic well-being, family support, community attachment, and life satisfaction among LGBQ adults. Journal of Family and Economic Issues, 37(4), 594-606.

Logie, C. H., Lacombe-Duncan, A., Lee-Foon, N., Ryan, S., \& Ramsay, H. (2016). "It's for us-newcomers, LGBTQ persons, and HIVpositive persons. You feel free to be": a qualitative study exploring social support group participation among African and Caribbean lesbian, gay, bisexual and transgender newcomers and refugees in Toronto, Canada. BMC International Health and Human Rights, 16(1), 1-10.

Martinez-Velez, J. J., Melin, K., \& Rodriguez-Diaz, C. E. (2019). A preliminary assessment of selected social determinants of health 
in a sample of transgender and gender nonconforming individuals in Puerto Rico. Transgender Health, 4(1), 9-17.

McGibbon, E. (2012). People under threat: health outcomes and oppression. In E. McGibbon (Ed.), Oppression: A Social Determinant of Health. (pp. 32-44). Fernwood Publishing.

McKenzie, C. (2015). "Is queer sex education in Ontario finally out of the closet?" Aporia: The Nursing Journal,73: 6-18.

Meyer, I. (2003). Prejudice, social stress, mental health in lesbian, gay, and bisexual populations: conceptual issues and research evidence. Psychological Bulletin, 129(5), 674-697.

Mikkonen, J., \& Raphael, D. (2010). Social Determinants of Health: The Canadian Facts. Toronto: York University School of Health Policy and Management. https://thecanadianfacts.org/The_Canadian_ Facts.pdf

Ministry of Health and Long-Term Care. (2009a). "Public Information-Ministry Programs.” Retrieved from http://www.health.gov. on.ca/en/public/programs/

Ministry of Health and Long-Term Care. (2009b). "Public Information-Publications." Retrieved from http://www.health.gov.on.ca/ en/public/publications/default.aspx

Ministry of Health and Long-Term Care. (2009c). "Public Information-HIV and AIDS: Gay and Bisexual Men." Retrieved from http://www.health.gov.on.ca/english/public/program/hivaids/ gay_bisexual.html

Ministry of Health and Long-Term Care. (2009d). "Public InformationPublications-HIV/AIDS.” Retrieved from http://www.health.gov. on.ca/en/public/publications/default.aspx

Ministry of Health and Long-Term Care. (2009e). "Public Information-HIV and AIDS in Ontario." Retrieved from http://www. health.gov.on.ca/english/public/program/hivaids/aids_mn.html

Ministry of Health and Long-Term Care. (2017a). "About the Ministry." Retrieved from http://www.health.gov.on.ca/en/common/ministry/ default.aspx

Ministry of Health and Long-Term Care. (2017b). "HIV and AIDS in Ontario.” Retrieved from http://www.health.gov.on.ca/en/public/ programs/hivaids/

Ministry of Health and Long-Term Care. (2017c). "Programs and Services.” Retrieved from http://www.health.gov.on.ca/en/public/ programs/default.aspx

Ministry of Health and Long-Term Care. (2017d). "Publications." Retrieved from http://www.health.gov.on.ca/en/public/publications/ default.aspx

Mississauga Halton LHIN. (2009). "Diverse Communities Consultations: April 23, 2009." Retrieved from http://www.mississaugahaltonlhin.on.ca/ /media/sites/mh/uploadedfiles/Home_Page/Integrated_ Health_Service_Plan/DiverseCommunities-FullCEReport.pdf

Mississauga Halton LHIN. (2014a). "Building Health Equity Capacity in the Mississauga Halton LHIN." Prepared by Sustainable Societies Consulting Group for Summit Housing and Outreach Services. Mississauga \& Halton, ON. Retrieved from http://www. mississaugahaltonlhin.on.ca/ /media/sites/mh/PrimaryNavigation/ GoalsAchievement/ProgramAreaandInitiatives/HealthEquity/ 2014HealthEquityProjectinal.pdf?la=en

Mississauga Halton LHIN. (2014b). "Partnering for a Healthy Community: Integrated Health Service Plan 2016-2019”. Retrieved from http://www.mississaugahaltonlhin.on.ca/goalsandachieve ments/ihsp.aspx

Mulé, N. J. (2005). Beyond words in health and wellbeing policy: 'sexual orientation'-from inclusion to infusion. Canadian Review of Social Policy, 55, 79-98.

Mulé, N. J., Ross, L. E., Deeprose, B., Jackson, B. E., Daley, A., Travers, A., \& Moore, D. (2009). Promoting LGBT health and wellbeing through inclusive policy development. International Journal for Equity in Health, 8(18), 1-11.
Mulé, N. J., Smith, M. (2014). Invisible populations: LGBTQs and federal health policy in Canada. Canadian Public Administration, 57(2), 234-255. https://doi.org/10.1111/capa.12066

Mulé, N. J. (2020). State involvement in LGBT+ health and social support issues in Canada. International Journal of Environmental Research and Public Health, 17(19), 1-12.

North East LHIN. (2016). "North East LHIN Board Package Board of Directors Meeting: Teleconference Wednesday September 21, 2016.” Received from http://www.nelhin.on.ca/Page.aspx?id= 5705C75A8A004A2B8C31E3ACF7615377

North Simcoe Muskoka LHIN. (2016). "2016-2017 Annual Business Plan.” Received from http://www.nsmlhin.on.ca/ /media/ sites/nsm/PrimaryNavigation/Accountability/NSM\%20ABP\% 201617E.pdf?la=en

Ontario Human Rights Code. (2020). The Ontario Human Rights Code. Received from http://www.ohrc.on.ca/en/ontariohuman-rights-code

Oster, A. M., Russell, K., Wiegand, R. E., Valverde, E., Forrest, D. W., Cribbin, M., Le, B. C., Paz-Bailey, G., \& NHBS Study Group. (2013). HIV infection and testing among Latino men who have sex with men in the United States: the role of location of birth and other social determinants. PLOS ONE, 8(9), 1-9.

Pakula, B., Carpiano, R., Ratner, P., \& Shoveller, J. (2016). Life stress as a mediator and community belonging as a moderator of mood and anxiety disorders and co-occurring disorders with heavy drinking of gay, lesbian, bisexual, and heterosexual Canadians. Social Psychiatry and Psychiatric Epidemiology, 51(8), 11811192. https://doi.org/10.1007/s00127-016-1236-1

Public Health Agency of Canada. (2015). "Summary: Estimates of HIV incidence, prevalence and proportion undiagnosed in Canada, 2014." Retrieved from https://www.canada.ca/content/dam/canada/ health-canada/migration/healthy-canadians/publications/diseasesconditions-maladies-affections/hiv-aids-estimates-2014-vih-sidaestimations/alt/hiv-aids-estimates-2014-vih-sida-estimations-eng. pdf

Public Health Agency of Canada. (2018). "Social Determinants of Health and Health Inequalities." Retrieved from https://www.canada.ca/en/ public-health/services/health-promotion/population-health/whatdetermines-health.html-determinants

Raphael, D. (2016). Social determinants of health: Canadian perspectives. Canadian Scholars' Press.

Raphael, D., Bryant, T., Mikkonen, J. \& Raphael, A. (2020). Social Determinants of Health: The Canadian Facts. Oshawa: Ontario Tech University Faculty of Health Sciences and Toronto: York University School of Health Policy and Management. Retrieved from https://thecanadianfacts.org/The_Canadian_Facts-2nd_ed. pdf

Ross, L.E. \& Khanna, A. (2017). "What are the Needs of Lesbian, Gay, Bisexual, Trans, And Queer LGBTQ+ People That Should Be Addressed by Canada's Poverty Reduction Strategy CPRS?'Toronto, ON: Dalla Lana School of Public Health. Retrieved from http:// lgbtqhealth.ca/projects/docs/prsjointsubmission.pdf

Scheim, A. I., Jackson, R., James, L., Dopler, T.S., Pyne, J., \& Bauer, G.R. "Barriers to Well-Being for Aboriginal Gender-Diverse People: Results from the Trans PULSE Project in Ontario, Canada." Ethnicity and Inequalities in Health and Social Care 6(4): $108-120$.

Schmitt, I. (2012). School policies, gender-sex-sexuality and ethnocultural re-production in Sweden, Canada, and Germany. In Z. Bekerman \& T. Geisen (Eds.), International Handbook of Migration, Minorities and Education. (pp. 365-381). Springer.

South East LHIN. (2009). "Engage 2009: A Qualitative Analysis of Thoughts, Ideas and Perceptions for IHSP2, Final Report.” Retrieved from https://www.google.ca/url?sa=t\& 
$\mathrm{rct}=\mathrm{j} \& \mathrm{q}=\& \mathrm{esrc}=\mathrm{s} \&$ source $=$ web $\& \mathrm{~cd}=7 \& \mathrm{cad}=\mathrm{rja} \& \mathrm{uact}=$ $8 \&$ ved=0ahUKEwiPjZum2PrVAhUf24MKHVCKDwsQFg hMMAY\&url=http $\% 3 \mathrm{~A} \% 2 \mathrm{~F} \% 2 \mathrm{Fwww}$.southeastlhin.on.ca\% 2F \%2Fmedia\%2Fsites\%2Fse\%2Fuploadedfiles\%2FHome_ Page\%2FAppendix\%25204a\%2520ENGAGE2009.pdf\&usg= AFQjCNHMZkVhRwa3k4kIfG_rCCDVcN-lmQ

South East LHIN. (2014a). "Welcome to SVP 102: Understanding the Social Determinants of Health.” Retrieved from http://www. southeastlhin.on.ca/GoalsandAchievements/Coordination/Healt hLinks/HealthLinkCareCoordinationLearningProgram/Servi ngVulnerablePopulations/SVP102/SVP102-page2.aspx

South East LHIN. (2014b). Understanding the social determinants of health. Retrieved from: http://www.southeastlhin.on.ca/ GoalsandAchievements/Coordination/HealthLinks/HealthLink CareCoordinationLearningProgram/ServingVulnerablePopulati ons/SVP102/SVP102-page10.aspx

South West LHIN. (2011). "The Time is Now: A Plan for Enhancing Community-Based Mental Health and Addiction Services in the South West LHIN." Retrieved from http://www.southwestl hin.on.ca/goalsandachievements/Programs/ /media/sites/sw/ uploadedfiles/PublicCommunity/CurrentInitiatives/MentalHealth/ CommunityCapacityReport-final_Nov16_2011.pdf

Statistics Canada. (2016). "Canadian Community Health Survey: Annual Component." Retrieved from http://www23.statcan.gc. $\mathrm{ca} / \mathrm{imdb} / \mathrm{p} 2 \mathrm{SV} \cdot \mathrm{pl}$ ? Function $=$ assembleDESurv\&DECId=379\& RepClass $=591 \& \mathrm{Id}=238854 \&$ DFId $=180541$

Statistics Canada. (2019). "Statistics Canada, Table 17-10-0005-0. Population Estimates on July 1st, by Age and Sex." Retrieved from https://doi.org/10.25318/1710000501-eng

Steele, L. S., Daley, A., Curling, D., Gibson, M. F.,Green, D. C., Williams, C. C., \& Ross, L. E. (2017). LGBT identity,untreated depression, and unmet need for mental health services by sexualminority women and trans-identified people. Journal of Women'sHealth, 26(2), 116-127.

Tjepkema, M. (2008). Health care use among gay, lesbian and bisexual Canadians. Journal of Health Reports, 19(1), 53-64.

Toomey R., \& Russell, S. (2011). Gay-straight alliances, social justice involvement and school victimization of lesbian, gay, bisexual, and queer youth: implications for school well-being and plans to vote. Youth \& Society, 45(4), 500-522.

Toronto Central LHIN. (2009). "Summary of Results from Consultations on Provincial Themes for Mental Health and Addictions." Retrieved from http://www.torontocentrallhin.on.ca/ /media/ sites/tc/Newmediafolder/CommunityEngagement/Reports/ MHASummaryonConsultations.pdf?la=en
Toronto Central LHIN. (2014). “Meet our Citizens’ Panel.” Retrieved from http://www.torontocentrallhin.on.ca/communityengagement/ citizenspanel/CitizensPanelBio.aspx

Toronto Central LHIN. (2016). "Strategic Plan, Year 2: 2015-2018." Retrieved from http://www.torontocentrallhin.on.ca/ /media/ sites/tc/New\%20media\%20folder/Goals\%20and\%20Achievem ents/Strategic\%20Plan\%202015-2018.pdf?la=en

Veale, J., Watson, R., \& PeterSaewyc., E., T. (2017). Mental health disparities among Canadian transgender youth. Journal of Adolescent Health, 60(1), 44-49.

Waite, S., Denier, N. (2015). Gay pay for straight work: mechanisms generating disadvantage. Gender \& Society, 29(4), 561-588

Waterloo-Wellington LHIN. (2009). "2010-2013 IHSP: Community Engagement Update.” Retrieved from http://www.waterloowe llingtonlhin.on.ca/ /media/sites/ww/files/boardandgovernance/ Meetings/archive/2009/April2009toMarch2010/082009-Aug20 2009/20090820WWLHIN2010-2013IHSPCommEngUpdatepres toBoard.pdf?la=en

Waterloo-Wellington LHIN. (2014). "Focus Group Summary: LGBTQ Advisory Committee." Retrieved from http://www. waterloowellingtonlhin.on.ca/en/goalsandachievements/ summaryinput/lgbtq_focusgroup.aspx

Wolff, M., Wells, B., Ventura-DiPersia, C., \& RensonGrov., C., A. (2017). Measuring sexual orientation: a review and critique of US data collection efforts and implications for health policy. The Journal of Sex Research, 54(4-5), 507-531.

World Health Organization. (1978). "Declaration of Alma-Ata: International Conference on Primary Health Care, Alma-Ata, USSR, 6-12 September 1978." Retrieved from http://www.who.int/publications/ almaata_declaration_en.pdf

Young, R. M., \& Meyer, I. H. (2005). The trouble with "MSM" and "WSW": erasure of the sexual-minority person in public health discourse. American Journal of Public Health, 95(7), 11441149. https://doi.org/10.2105/AJPH.2004.046714

Zanin, A. (2009). "Oppression by omission.” Xtra Online Newspaper. Retrieved from https://www.dailyxtra.com/oppression-byomission-12351

Zeeman, L., Aranda, K., Sherriff,N., \& Cocking, C. (2017). Promoting resilience and emotional well-being oftransgender young people: research at the intersections of gender andsexuality. Journal of Youth Studies, 20(3),382-397.

Publisher's Note Springer Nature remains neutral with regard to jurisdictional claims in published maps and institutional affiliations. 